\title{
A New Report of a Mosaic Dwarf Viroid-Like Disease on Mulberry Trees in China
}

\author{
WEN-BING WANG ${ }^{1 *}$, JIAN-MING FEI ${ }^{2}$, YAN WU ${ }^{1}$, XI-CHUAN BAI ${ }^{3}$, FENG YU $^{1}$, \\ GUO-FANG SHI ${ }^{2}$, YU-FENG LI ${ }^{2}$, YUAN-ZHANG KUAI ${ }^{4}$
}

\author{
${ }^{1}$ Institute of Life Science, Jiangsu University, Zhenjiang 212013, China \\ ${ }^{2}$ Academy of Agricultural Science, Huzhou City, Huzhou 313000, China \\ ${ }^{3}$ Huzhou Station of Silkworm and Mulberry Technical Guidance, Huzhou 313000, China \\ ${ }^{4}$ Sericultural Research Institute, Chinese Academy of Agricultural Sciences, Zhenjiang 212018, China
}

Received 10 May 2009, revised 6 December 2009, accepted 15 December 2009

\begin{abstract}
A viroid-like disease causing mosaic leaves and dwarfism was found on mulberry plants in Zhejiang, China. Grafting of stems from infected plants onto healthy plants resulted in the same symptoms on the healthy plants. A circular small RNA (Mmd-v RNA1) was isolated from the infected plant leaves and caused identical symptoms after more than two years. Nucleotide sequencing indicated that the Mmd-v RNA1 contains $356 \mathrm{nt}$ (GenBank accession no. NC_011362) without viroid characteristic regions, only sharing $30 \mathrm{nt}$ sequence identity with that of the Cherry small circular viroid-like RNA 1 (isolate cscRNA1.150, GenBank accession no. DQ357628). This description is the first of viroid-like RNA infection of mulberry trees.
\end{abstract}

Key words: Mmd-v RNA1, viroid infection, circular RNA, RT-PCR.

\section{Introduction}

Viroids are the smallest and simplest pathogens and found to only infect plants. They consist of a single-stranded, circular, naked RNA genome, and lack protein-coding sequences (Diener, 1991; Flores et al., 1998; Tabler and Tsagris, 2004). Different viroids range between 246 and 401 nucleotides in length, and most of them are rich in GC content (53-60\%) and form extensive intramolecular base pairings that result in a rod-like structure (Daros et al., 2006; Flores et al., 1998; Flores et al., 2004). Since the initial discovery of the Potato spindle tuber viroid (PSTVd), approximately 30 viroids have been found worldwide and classified into two families: the Pospiviroidae and the Avsunviroidae (Tabler and Tsagris, 2004). Viroids in the family Pospiviroidae contain a central conserved region (CCR) in their RNA molecule and replication takes place in the nucleus. On the other hand, members of the family Avsunviroidae lack $\mathrm{CCR}$, replicate in the chloroplast and are able to selfcleave through hammerhead ribozymes (Flores and Pallas, 2006).
Viroids have significant implications for agriculture (Diener, 2001). Many graft-transmissible tree diseases are known to be caused by viroids (Flores et al., 2005), but no viroids have so far been isolated from mulberry tree.

The silk industry is one of the most important economics in the developing countries. Silkworm larvae feed on the leaves of mulberry trees. Mulberry trees have been grown above ten centuries in the world. Here, we report the molecular and biological characterization of a new viroid-like RNA from mulberry tree.

\section{Experimental}

\section{Materials and Methods}

Transmissibility. Graft inoculation was performed independently in ten mulberry trees. Stem scions of diseased mulberry plants were inserted into a knife cut in the stem of root-stock plants of mulberry.

RNA extracted. Leaf tissue of mulberry $(10 \mathrm{~g})$ was homogenised in an extraction buffer containing

* Corresponding author: Y.Z. Kuai, Sericultural Research Institute, Chinese Academy of Agricultural Sciences, Zhenjiang, China; phone: (+86) 511-856 166 63; e-mail: kyz2006@sina.com 
$40 \mathrm{ml}$ of water-saturated phenol and $10 \mathrm{ml}$ of Tris buffer (125 mM Tris-HCl, pH 8.9, $15 \mathrm{mM}$ EDTA, $0.8 \%(\mathrm{w} / \mathrm{v})$ SDS, $0.8 \%(\mathrm{v} / \mathrm{v}) \quad \beta$-mercaptoethanol) (Pallás, 1987) and the total nucleic acids were partitioned in methoxyethanol (Semancik et al., 1975). The preparations were further purified by non-ionic cellulose chromatography (Franklin, 1966; Semancik, 1986). Specifically, the preparations were resuspended in STE buffer (50 mM Tris-HCl, pH 7.2, 0.1 M $\mathrm{NaCl}, 1 \mathrm{mM}$ EDTA) containing $35 \%$ ethanol and mixed with non-ionic cellulose CF-11 (Whatman). The cellulose was washed three times with STE containing 35\% ethanol, and the RNAs bound to the cellulose were eluted with STE and concentrated by ethanol precipitation.

R-PAGE. RNA extracts were separated by returnpolyacrylamide gel electrophoresis (R-PAGE) under nondenaturing and denaturing conditions, and revealed by silver staining (Igloi, 1983; Rivera, 1986). In the first running, the gel was kept in running buffer at room temperature, and in the return running, the temperature of the running buffer was raised at $70^{\circ} \mathrm{C}$.

cDNA synthesis. By using a denaturing gel to separate the purified RNA and staining with ethidium bromide, the specific RNA band was cut out, and the viroid-like RNA was eluted overnight with TEP buffer $(0.1 \mathrm{M}$ Tris-HCl, $\mathrm{pH}$ 9.0, containing $0.1 \mathrm{M}$, $\beta$-mercaptoethanol, $10 \mathrm{mM}$ EDTA, and $1 \%$ SDS) in the presence of phenol/chloroform. The RNA was recovered by ethanol precipitation and resuspended in water. The purified circular forms of RNA were denatured in buffer $(10 \mathrm{mM}$ Tris- $\mathrm{HCl}, \mathrm{pH} 8.5,20 \mathrm{mM}$ $\mathrm{KCl}$ ) at $95^{\circ} \mathrm{C}$ for $2 \mathrm{~min}$. First-strand cDNA was synthesised with $25 \mathrm{U}$ of avian myeloblastosis virus reverse transcriptase (AMV-RT), using random primers. The reaction mixture ( $20 \mu \mathrm{l}$ final volume) was incubated at $42^{\circ} \mathrm{C}$ for $45 \mathrm{~min}$. Second-strand cDNA synthesis and PCR amplification ( $25 \mu 1$ final volume) was performed using $2 \mu \mathrm{l}$ of the first-strand cDNA reaction mixture, 2.5 U Pfx DNA polymerase (Invitrogen). The phosphorylated primers were designed for amplification of the fragment in the conserved regions of viroids. They were: P1-for, GTC CTC GAA TGT AC; and P2-Re, CCG CCA GCT GAG CA. PCR conditions consisted of 30 cycles of $95^{\circ} \mathrm{C}$ for $30 \mathrm{~s}$, $55^{\circ} \mathrm{C}$ for $30 \mathrm{~s}$ and $72^{\circ} \mathrm{C}$ for $1 \mathrm{~min}$, with a final extension at $72^{\circ} \mathrm{C}$ for $10 \mathrm{~min}$. The amplified products were detected by $2 \%$ agarose gel, and were eluted and ligated into the Sma I site of plasmid pUC18. Escherichia coli cells were used for plasmid cloning.

Splicing of full length sequence of the RNA molecule. To verify the full length sequence, two other primers were designed to amplify the RNA fragment. The primers were: P3-for, GTC CAG ACA CAC ATC T, homologous to 247-262 nt; and P4-re, TGA TGA GTT CGA AAG AAC, complementary to 228-246 nt, respectively. The PCR products were analyzed by electrophoresis in $2.0 \%$ agarose gel, stained with ethidium bromide and visualized under UV light. The amplified fragments were cloned and sequenced. The sequence data were compared and spliced into the full length sequence.

Structure prediction of the RNA. Possible secondary structures of the RNA were calculated at folding temperatures of 25,30 , and $37^{\circ} \mathrm{C}$ using the program mfold (Zuker, 2003), version 2.3, from http:// frontend.bioinfo.rpi.edu/applications/mfold/cgi-bin/ rna-form1-2.3.cgi.

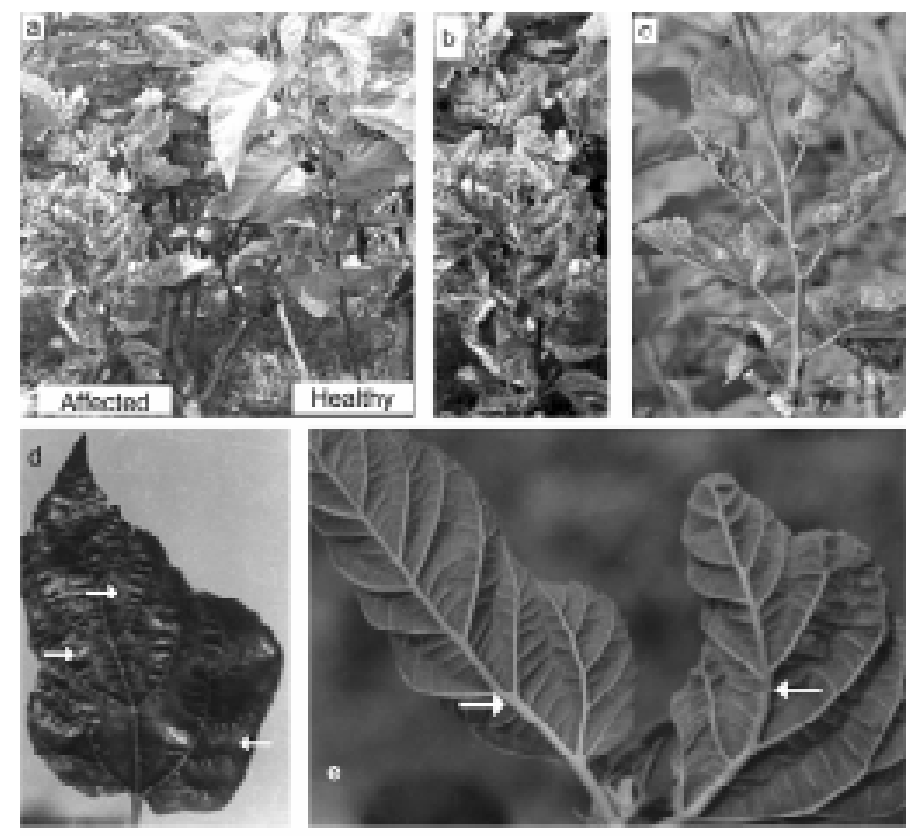

Fig. 1. Symptoms of infected mulberry trees.

a) infected mulberry tree (left) compared with a healthy tree (right); b) the mulberry tree was infected after 2 years by inoculation with purified RNA; c) the infected tree by grafting assay; d) typical symptom of mosaic leaf; e) protuberances on the leaf nervation. The arrows indicate the infection symptom. 

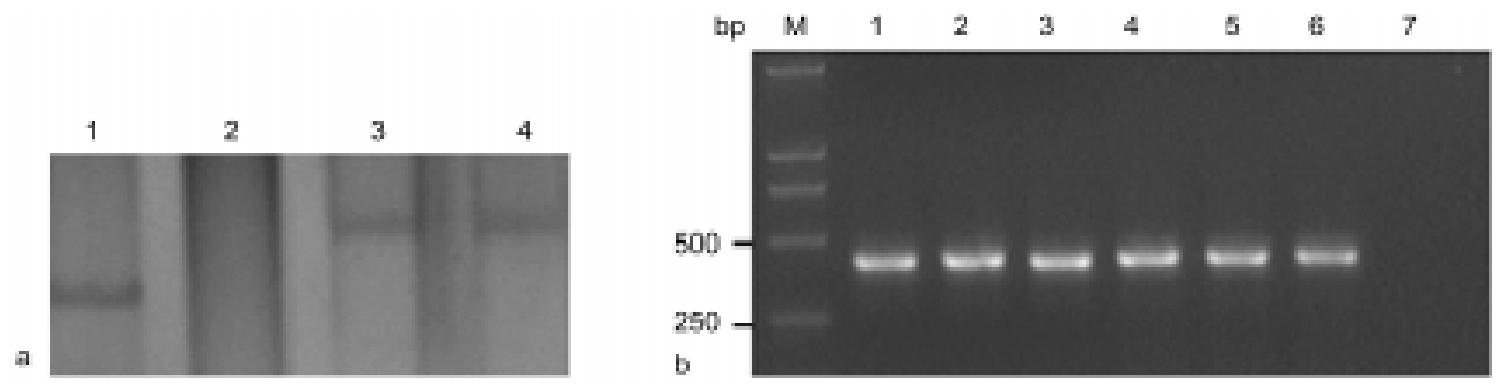

Fig. 2. Detection of the viroid specific bands.

a) by R-PAGE. 1 - PSTVd RNA as a control; 2 - RNA from healthy mulberry tree; 3 and 4 - RNA from infected mulberry trees; b) reverse transcription and polymerase chain reaction products amplified with P3 and P4 primer pairs, M - DNA molecular markers; 1 - infected mulberry tree by inoculation in Zhenjiang test field; 2 - diseased mulberry tree in Huzhou; 3-6 - infected mulberry tree by inoculation in Huzhou test field; 7 - th healthy mulberry tree in Huzhou.

\section{Results and Discussion}

In the 1990's, diseased mulberry trees with symptoms typical of viroid infection, such as mosaic leaves, protrusions on the leaf nervation and dwarfism, were noted in some mulberry fields in Zhejiang Province, China (Fig.1a, d and e). Recently, the disease became severely and spread out of the main silkworm-cultured areas. In fields, the symptoms firstly appeared in the individuals and sequentially spread out along the plant rows. By graft inoculation, after two months, the leaves of the stock plants bore symptoms resembling those of the source plants (Fig. 1c). These evidences indicated that the symptoms were due to a pathogen infection, not a physiological disorder. However, after observations of infected leaves with an electron microscope, the ultra-thin sections of the diseased leaves failed to reveal any visible agents.

According to the symptoms of the disease, we speculated on that might be caused by virus or viroid. Since none of viral particles could be observed by microscope, it indicated that the pathogen might be

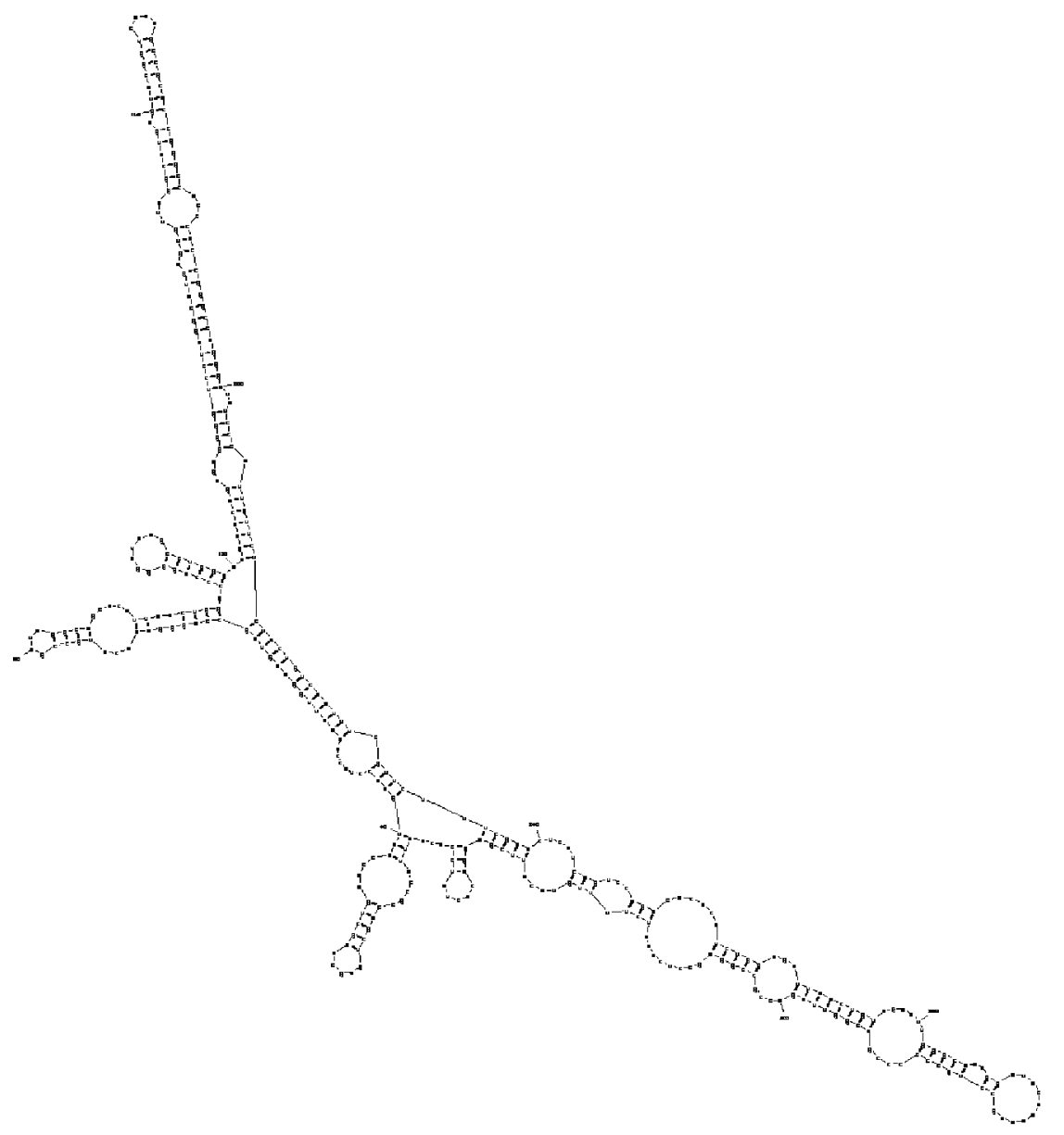

Fig. 3. The proposed secondary structure of Mmd-v RNA1.

The RNA sequence of Mmd-v RNA1 was arranged in a rod-like structure by the $m$ fold program. It contains a small, circular RNA, but lacks viroid specific regions, such as the terminal conserved region (TCR), the central conserved region (CCR). 
viroid. Hence, R-PAGE was used to detect the viroid RNA molecules. The result indicated that an RNA band appeared in the lanes of infected samples (Fig. 2a). We used the purified RNA to infect seven mulberry trees in a separated garden of a small town near Huzhou area. After two years, three mulberry trees had the typical infected symptoms. The results indicated that this RNA (named as Mmd-v RNA1) is related to the mulberry tree infection (Fig. 1b).

Viroid pathogens are known to be transmissible by mechanical injury of host cells and, also by the tools or agrotechnique used for agricultural treatments of crops or during picking operations (Flores and Pallas, 2006). Pruning of mulberry treetop by scissors to prevent wound by cold in winter, and cutting off the mulberry tree branches after the leaf harvest in the spring might be the main reasons for the disease spread.

The result of PCR analysis indicated that the infected trees contain specific viroid-like RNA molecules (Fig. 2b). Complete sequencing of the sixteen clones revealed that the RNA molecule contains 356 nucleotides (GenBank accession no. NC_011362), only sharing a high identity in 224-262 nt with that of the Cherry small circular viroid-like RNA 1 (isolate cscRNA1.150, GenBank accession no. DQ357628) in 246-284 nt. Figure 3 shows the nucleotide sequence and the proposed secondary structure of Mmd-v RNA1. The mfold program predicted the most stable secondary structure as the rod-like structure at all folding temperatures tested (Fig. 3). Overall, 58.4\% of the bases are paired and the paired residues consist of $51.9 \% \mathrm{GC}, 37.5 \% \mathrm{AU}$, and $10.6 \%$ GU pairs. However, Mmd-v RNA1 lacks the viroid characteristic regions, such as the terminal conserved region (TCR) (CNNGNGGUUCCUGUGG) and the CCR (Nakaune and Nakano, 2008).

In this paper, we firstly reported that the mulberry mosaic dwarf disease was infectant and a circular, small RNA might be the main cause for infection. However, the sequence of the RNA was different with those of the reported viroids and viroid-like satellite RNAs. It lasts a long time, more than two years for the typical symptoms appearing on the mulberry trees. The pathogen was difficult to identify according to Kohn's postulates, in which the microorganism must be present in every case of the disease and the same microorganism must be isolated again from the diseased host caused by infection of the microorganism (Prescott et al., 1996). Although we have no more information about the pathogen RNA, our findings may help to detect the origin and the disease. Further study on RNA variants in other areas and geographic distribution of the disease is necessary to reveal the infection mechanisms.

\section{Acknowledgments}

We thank Prof. JI-CAI YANG (Institute of Microbiology, Chinese Academy of Sciences) for technical support and the sample RNA of PSTVd. This work was supported by a grant from Zhejiang Province (2008C22029)

\section{Literature}

Daros J.A., S.F. Elena and R. Flores. 2006. Viroids: an Ariadne's thread into the RNA labyrinth; EMBO Rep. 7: 593-598.

Diener T.O. 1991. Subviral pathogens of plants: Viroids and viroid-like satellite RNAs; FASEB J. 5: 2808-2813.

Diener T.O. 2001. The viroid: biological oddity or evolutionary fossil; Adv. Virus Res. 57: 137-184.

Flores R., S. Delgado, M.E. Gas, A. Carbonell, D. Molina, S. Gago and M. De la Penã. 2004. Viroids: the minimal non-coding RNAs with autonomous replication; FEBS Lett. 567: 42-48. Flores R. and V. Pallas. 2006. Viroids. In Khan J A and Dijkstra J. (Eds.) Handbook of plant virology (New York, USA: The Haworth Press).

Flores R., J.W. Randles, M. Bar-Joseph and T.O. Diener. 1998 A proposed scheme for viroid classification and nomenclature; Arch. Virol. 143: 623-629.

Flores R., J. W. Randles, R.A. Owens, M. Bar-Joseph and T.O. Diener. 2005. Subviral agents: viroids In: C.M. Fauquet, M.A. Mayo, J. Maniloff, U. Desselberger and L. A. Ball (eds) Virus taxonomy VIII (New York: Academic Press).

Franklin R.M. 1966. Purification and properties of the replicative intermediate of the bacteriophage R17; Proc. Natl. Acad. Sci. USA 55: 1504-1511.

Igloi G.L. 1983. Silver stain for the detection of nanogram amounts of tRNA following two-dimensional electrophoresis; Anal. Biochem. 134: 184-188.

Nakaune R. and M. Nakano. 2008. Identification of a new Apscaviroid from Japanese persimmon; Arch. Virol. 153: 969-972. Pallás V., V. Navarro and R. Flores. 1987. Isolation of viroidlike RNA from hop different from hop stunt viroid; J. Gen. Virol. 68: 3201-3205.

Prescott L.M., J.P. Harley and D.A. Klein. 1996. Microbiology $3^{r d}$; pp. 8-9 (the U. S. A.: Wm. C. Brown Publishers).

Rivera-Bustamante R.F., R. Gin and J.S. Semancik. 1986 Enhanced resolution of circular and linear molecular forms of viroid and viroid-like RNA by electrophoresis in a discontinuouspH system; Anal. Biochem. 156: 91-95.

Semancik J.S. 1986. Separation of viroid RNAs by cellulose chromatography indicating conformational dinstinctions. Virol. 155: 39-45.

Semancik J.S., T.J. Morris, L.G. Weathers, G. F. Rordorf and D.R. Kearns. 1975. Physical properties of a minimal infectious RNA (viroid) associated with the exocortis disease; Virol. 63: 160-167.

Tabler M. and M. Tsagris. 2004. Viroids: petite RNA pathogens with distinguished talents; Trends Plant Sci. 9: 339-348.

Zuker M. 2003. Mfold web server for nucleic acid folding and hybridization prediction. Nucleic Acids Res. 31: 3406-3415. 